\title{
Novel Scaffolds Fabricated Using Oleuropein for Bone Tissue Engineering
}

\author{
Hui Fan, ,2 Junfeng Hui, ${ }^{1,2}$ Zhiguang Duan,, ${ }^{1,2}$ Daidi Fan,, ${ }^{1,2}$ Yu Mi, \\ Jianjun Deng, ${ }^{1,2}$ and Hui Li ${ }^{1,2}$ \\ ${ }^{1}$ Shaanxi Key Laboratory of Degradable Biomedical Materials, School of Chemical Engineering, Northwest University, \\ 229 Taibai North Road, Xian 710069, China \\ ${ }^{2}$ Shaanxi R\&D Center of Biomaterials and Fermentation Engineering, School of Chemical Engineering, \\ Northwest University, Xian 710069, China
}

Correspondence should be addressed to Daidi Fan; fandaidi@nwu.edu.cn and Yu Mi; mi_yu@nwu.edu.cn

Received 13 December 2013; Revised 10 March 2014; Accepted 29 March 2014; Published 13 May 2014

Academic Editor: Costantino Del Gaudio

Copyright (C) 2014 Hui Fan et al. This is an open access article distributed under the Creative Commons Attribution License, which permits unrestricted use, distribution, and reproduction in any medium, provided the original work is properly cited.

\begin{abstract}
We investigated the feasibility of oleuropein as a cross-linking agent for fabricating three-dimensional (3D) porous composite scaffolds for bone tissue engineering. Human-like collagen (HLC) and nanohydroxyapatite (n-HAp) were used to fabricate the composite scaffold by way of cross-linking. The mechanical tests revealed superior properties for the cross-linked scaffolds compared to the uncross-linked scaffolds. The as-obtained composite scaffold had a 3D porous structure with pores ranging from 120 to $300 \mu \mathrm{m}$ and a porosity of $73.6 \pm 2.3 \%$. The cross-linked scaffolds were seeded with MC3T3-E1 Subclone 14 mouse osteoblasts. Fluorescence staining, the Cell Counting Kit-8 (CCK-8) assay, and scanning electron microscopy (SEM) indicated that the scaffolds enhanced cell adhesion and proliferation. Our results indicate the potential of these scaffolds for bone tissue engineering.
\end{abstract}

\section{Introduction}

The need for bone grafts to repair skeletal defects caused by trauma or bone neoplasia has been constantly increasing in recent years. Currently, autologous bone grafts and allografts are the main options for bone replacement. Although autologous bone grafts are ideal for osteoinduction and osteogenesis, they require secondary surgery, are available in very limited supplies, and can lead to donor site morbidity $[1,2]$. In addition, allografts can potentially result in disease transmission and immune responses. All of these factors limit their application in bone reconstruction. To overcome these limitations, various bone tissue engineering strategies have been proposed. The ideal scaffold for use as a transplant not only has good biocompatibility, appropriate mechanical properties, and a well-matched degradation rate [3-5] but also has an appropriate pore size and high interconnectivity to promote cells attachment, proliferation, and bone repair [6-10].
To provide a biocompatible and bioactive environment for new bone formation, a wide variety of materials have been used to mimic the bone-forming components. As the main structural element in skin, bone, tendon, cartilage, blood vessels, and heart valves, collagen has been widely used in tissue engineering. Human-like collagen (HLC) is a recombinant collagen expressed by recombinant Escherichia coli BL21 [11], which contains a modified cDNA reversetranscribed from human collagen mRNA. Due to the water solubility, workability, low immunogenicity, biocompatibility, and biodegradability of HLC, this material has been successfully used for vascular scaffolds [12, 13], artificial bone [14], hydrogels [15], and skin tissues [16]. As the major components of human natural bone, nanohydroxyapatite (nHAp) possesses excellent biocompatibility, osteoconductivity, and bioactivity and lacks antigenicity and cytotoxicity. Thus, $\mathrm{n}$-HAp is an outstanding biomaterial for guided bone regeneration $[17,18]$. 
In addition, the cross-linking technique can increase the mechanical properties of the scaffolds. Chemical crosslinking agents, such as carbodiimide or glutaraldehyde, have been studied extensively for biomedical applications. However, their high cytotoxicity may influence the biocompatibility of the scaffolds [19]. Thus, the development of a natural noncytotoxic cross-linking agent is urgently needed. Simple phenolic compounds derived from plants have been studied for cross-linking proteins [20]. However, little attention has been focused on polyphenol as a crosslinking agent for bone tissue engineering. Furthermore, oleuropein, a polyphenol belonging to the secoiridoid class, the most representative catecholic components of olives, possesses high antioxidation ability due to its ability to scavenge superoxide radicals. Antioxidant nutrients might reduce the production of free radicals, contributing to bone resorption and enhancing bone formation. It has been demonstrated that oleuropein elicits protective effects on bone [21].

In this study, oleuropein was employed as a cross-linking agent for bone tissue engineering using cross-linked composite HLC/n-HAp scaffolds. The characteristics and mechanical properties of the scaffolds and their ability to promote cell adhesion and proliferation were investigated.

\section{Materials and Methods}

2.1. Materials. HLC was supplied from Juzi Biogene Technology Co. Ltd. (97,000 Da, Xi'an, China) and n-HAp was supplied by Epri Nano Materials Ltd. Co. $(20 \mathrm{~nm}$, Nanjing, China). Oleuropein was supplied by Wedar Ltd. Co. (Shanghai, China). MC3T3-E1 cells were obtained from Biok\&KM Co. Ltd. (Jiangsu, China). Trypsin (250 units/mg) was obtained from Amresco (Solon, OH, USA). Minimum essential medium (MEM) and fetal bovine serum (FBS) were purchased from Hyclone (Logan, UT, USA). The Cell Counting Kit-8 (CCK-8) was obtained from Keygen Biological Technology Development Co. Ltd. (KGA317, Nanjing, China). All other reagents and solvents were of analytical grade.

\subsection{Preparation of Composite HLC/n-HAp Scaffolds. HLC} was dissolved in deionized distilled water at a concentration of $4.8 \%(\mathrm{w} / \mathrm{v})$ by gentle stirring at room temperature for $30 \mathrm{~min}$. The $\mathrm{n}$-HAp (HLC/n-HAp ratio $=1: 2,1: 3,1: 4,1: 5$, and $1: 6(\mathrm{w} / \mathrm{w}))$ was then dispersed in the HLC solution. The HLC/n-HAp mixture was transferred into a mold, which was successively frozen at $4^{\circ} \mathrm{C}$ for $20 \mathrm{~min},-20^{\circ} \mathrm{C}$ for $1 \mathrm{~h}$, and $-70^{\circ} \mathrm{C}$ for $3 \mathrm{~h}$. After lyophilization in a vacuum freezedryer (FD 5-10, SIM, USA) for $48 \mathrm{~h}$ at $6.7-13.3 \mathrm{~Pa}$ (50100 mTorr), the as-obtained scaffolds were cross-linked using an oleuropein ethanol-water solution (concentration of $0.5 \%$, $1 \%, 1.5 \%, 2 \%, 2.5 \%$, and $3 \%(\mathrm{w} / \mathrm{v})$ and $90 \%$ ethanol) at $37^{\circ} \mathrm{C}$ for $36 \mathrm{~h}$. The scaffolds were then washed under running deionized distilled water for $3 \mathrm{~h}$ to remove the ethanol and again lyophilized for $48 \mathrm{~h}$. The scaffolds were applied to subsequent experiments.
2.3. Scanning Electron Microscopy (SEM). The surface morphologies of the composite HLC/n-HAp scaffolds were examined by scanning electron microscopy (Hitachi S-570, Japan). Before imaging, the scaffolds were cut into pieces with a razor blade, which were mounted on aluminum stubs and sputtercoated with gold.

2.4. Mechanical Properties of the HLC/n-HAp Scaffolds. The mechanical property of the composite HLC/n-HAp scaffolds was determined by measurement of the compression strength and Young's modulus using an INSTRON 5565 Materials Testing System with a $5000 \mathrm{~N}$ load cell. To test the longitudinal compression strength, the loading rate was $1 \mathrm{~mm} / \mathrm{min}$. Five samples were measured for each group. Cylindrical samples were prepared with diameters of $10 \mathrm{~mm}$ and lengths of $30 \mathrm{~mm}$.

2.5. X-Ray Diffraction (XRD). The crystalline phase of the scaffold was analyzed by X-ray diffraction (Rigaku D/max3C, Japan). The phases were identified by comparison to the n-HAp X-ray diffractograms. The scaffold was ground to a powder and analyzed. The XRD data were acquired using a voltage of $40 \mathrm{kV}$ at a rate of $2^{\circ} / \mathrm{min}$ and angle range of $10-60^{\circ}$.

2.6. Fourier Transform Infrared Spectra (FTIR). The chemical structures of the composite HLC/n-HAp scaffold, HLC, and n-HAp were characterized using a Fourier transform infrared spectrophotometer (EQUINOX-55, Bruker Corporation, Germany) using the $\mathrm{KBr}$ method. FTIR spectra were collected from 4000 to $500 \mathrm{~cm}^{-1}$.

2.7. Thermogravimetric Analysis (TGA). The thermal stability of the composite scaffolds was evaluated by thermogravimetric analysis (STA449C, Netzsch) with a heating rate of $3^{\circ} \mathrm{C} / \mathrm{min}$ from $30^{\circ} \mathrm{C}$ to $600^{\circ} \mathrm{C}$.

2.8. Scaffold Porosity. The porosity of the scaffold was measured by liquid displacement, as calculated according to $P=$ $\left(W_{1}-W_{0}\right) / \rho V_{0}$, where $W_{1}$ is the wet weight of the scaffold after it is immersed in the dehydrated alcohol for $48 \mathrm{~h}$ until it is saturated, $W_{0}$ is the dry weight of the scaffold, $\rho$ is the density of the dehydrated alcohol, and $V_{0}$ is the volume of the scaffold. Three parallel samples were tested.

2.9. Cell Seeding and Culture. MC3T3-E1 Subclone 14 mouse osteoblasts were used to evaluate cell proliferation and morphology on the scaffolds. MC3T3-E1 cells were cultured in minimum essential medium (MEM) including $10 \%$ heatinactivated FBS in a 95\% relative humidity atmosphere of $5 \% \mathrm{CO}_{2}$ at $37^{\circ} \mathrm{C}$. The composite scaffolds were cut into circular disks of $10 \mathrm{~mm}$ diameter and $3 \mathrm{~mm}$ height. The pieces were placed in 48-well culture plates and sterilized by $\mathrm{Co}_{60}$ irradiation. Before cell seeding, the scaffolds were prewetted with MEM for $24 \mathrm{~h}$ to displace air from the scaffolds. The MC3T3-E1 cells were digested by trypsin/EDTA solution and suspended in MEM at a concentration of $1 \times 10^{6} \mathrm{cell} / \mathrm{mL}$. A total of $50 \mu \mathrm{L}$ of cell suspension was seeded onto each scaffold 
surface. The seeded scaffolds were incubated at $37^{\circ} \mathrm{C}$ with $5 \%$ $\mathrm{CO}_{2}$ to allow cells to attach. After $4 \mathrm{~h}$, an additional $1 \mathrm{~mL}$ of medium was added to each well. The culture medium was refreshed every two days. After 3, 7, and 14 days, the cellscaffold constructs were analyzed.

2.10. Cell Viability and Proliferation. Evaluation of the cell viability and proliferation on the scaffolds was performed by fluorescence staining and the CCK-8 assay. For fluorescence staining, each cell-scaffold was carefully washed with PBS and the nuclei were stained with $4^{\prime}, 6$-diamidino-2-phenylindole (DAPI) solution (1:1000 DAPI in PBS) for $10 \mathrm{~min}$. The cellscaffolds were analyzed using a fluorescence microscope (TS100, Nikon, Japan). For the CCK-8 assay, the cell-seeded scaffolds were transferred to new 48 -well plates and incubated with $1 \mathrm{~mL}$ fresh MEM medium containing $10 \mu \mathrm{L} \mathrm{CCK}-8$ at $37^{\circ} \mathrm{C}$ with $5 \% \mathrm{CO}_{2}$ for $3 \mathrm{~h}$. An unseeded scaffold was used as a control. A total of $100 \mu \mathrm{L}$ of reaction liquid was transferred to a 96-well plate to measure the absorbance at $450 \mathrm{~nm}$ using a microplate reader (Power Wave XS2, Gene Company, USA). Scaffolds with medium but without cells were used to assess the background absorbance. The degree of cell proliferation was determined after 3, 7, and 14 days of culture. Five cellscaffold constructs were tested each time.

2.11. Morphological Analysis. Scanning electron microscopy was used to observe the morphology of cells adhered to the scaffolds. After 7 and 14 days of culture, the cellseeded scaffolds were rinsed with PBS and fixed with $2.5 \%$ glutaraldehyde in phosphate buffer $\left(\mathrm{pH} \mathrm{7.4)}\right.$ at $4^{\circ} \mathrm{C}$ for $4 \mathrm{~h}$. The scaffolds were dehydrated in increasing concentrations of ethanol $(30 \%, 50 \%, 70 \%, 90 \%, 95 \%$, and 100\%) and critically point-dried. The dried cell-scaffolds were mounted on aluminum stubs and sputter-coated with gold for SEM.

2.12. Statistical Analysis. The data were analyzed using the Statistical Analysis System (SAS 9.0) package software for analysis of variance using Duncan's test. All experiments were carried out in triplicate. Significance was established at $P \leq$ 0.05 .

\section{Results}

3.1. Effects of Processing Parameters on the Properties of Scaffolds. The porosity for the different samples is reported in Table 1. With the ratio of HLC to n-HAp decreasing from $1: 2$ to $1: 6$, the porosity of the scaffolds decreased from approximately $89.3 \pm 4.1 \%$ to $51.57 \pm 1.5 \%$. This was coincident with the SEM images of the different samples, as shown in Figure 1. The samples with ratios of $1: 2,1: 3$, and $1: 4$ had homogeneous pores that were interconnected. The samples with ratios of 1:5 and 1:6 had weakly interconnected pores that were inhomogeneous. The effects of different composites and the oleuropein concentration on the compressive strength and Young's modulus were investigated. As shown in Figure 2(a), increasing the n-HAp content of the scaffolds to $80 \mathrm{wt} . \%$ increased the compressive strength and Young's modulus to $2.97 \pm 0.19 \mathrm{MPa}$ and $43.03 \pm 6.17 \mathrm{MPa}$, respectively.
TABLE 1: Porosity of the composite scaffolds with different n-HAp contents.

\begin{tabular}{lc}
\hline HLC $:$ n-HAp ratio $(w / w)$ & Porosity $(\%)$ \\
\hline $1: 2$ & $89.3 \pm 4.1$ \\
$1: 3$ & $81.2 \pm 2.8$ \\
$1: 4$ & $73.6 \pm 2.3$ \\
$1: 5$ & $60.8 \pm 2.0$ \\
$1: 6$ & $51.6 \pm 1.5$ \\
\hline
\end{tabular}

When the n-HAp content of the scaffolds was more than 80 wt.\%, the brittleness of the scaffolds increased significantly. As shown in Figure 2(b), when the concentration of oleuropein solution reached $2 \%(\mathrm{w} / \mathrm{v})$, the compressive strength and Young's modulus reached maximums of $2.97 \pm 0.19 \mathrm{MPa}$ and $43.03 \pm 6.17 \mathrm{MPa}$, respectively. The composite scaffold with a porosity of $73.6 \pm 2.3$ and a compressive strength of $2.97 \pm 0.19$ was used for subsequent characterization and cell culture. The effect of the sterilization procedure by $\mathrm{Co}_{60}$ irradiation on the HLC/n-HAp scaffold (HLC : $\mathrm{n}-\mathrm{HAp}=$ $1: 4$, with concentration of oleuropein being $2 \%$ ) was also investigated.

3.2. Morphology of the HLC/n-HAp Composite Scaffolds. The macroscopic view and the morphology of the HLC/nHAp scaffolds are shown in Figures 3 and 4, respectively. The scaffolds (before and after $\mathrm{Co}_{60}$ irradiation) had $3 \mathrm{D}$ porous structures with homogeneous pores ranging from 120 to $300 \mu \mathrm{m}$ and the porosity was $73.6 \pm 2.3 \%$. The pores were interconnected, which might be helpful for water and nutrient transport. On the walls of the macropores there were smaller pores, with pore sizes less than $6 \mu \mathrm{m}$. The $\mathrm{Co}_{60}$ irradiation sterilization procedure did not have any obvious influence on the scaffold morphology.

3.3. Characterization of the HLC/n-HAp Composite Scaffolds. Compression tests were conducted to assess the mechanical performance of the scaffolds. The compressive strength of the HLC/n-HAp scaffolds was enhanced by cross-linking, which indicated that the cross-linking process contributed to the superior mechanical properties of the scaffolds. Figure 5(a) shows the mechanical properties of the scaffolds before and after the sterilization by $\mathrm{Co}_{60}$ irradiation. There was no obvious difference in the mechanical properties of the scaffold after sterilization.

As shown in Figure 5(b), the composite scaffolds displayed sharp and intense diffraction peaks at $25.8^{\circ}, 31.8^{\circ}, 33^{\circ}$, $34^{\circ}, 39.8^{\circ}, 46.7^{\circ}$, and $49.4^{\circ}$, which confirmed the presence of hydroxyapatite.

Figure 5(c) shows the FT-IR spectra of the scaffolds (before and after $\mathrm{Co}_{60}$ irradiation), along with the spectra for n-HAp and HLC. In the n-HAp spectra, an absorption band associated with the $-\mathrm{OH}$ stretching vibration mode is clearly seen at $3436 \mathrm{~cm}^{-1}$. The peaks at approximately 1039 , 602 , and $567 \mathrm{~cm}^{-1}$ were assigned to $\mathrm{PO}_{4}{ }^{3-}$. The characteristic absorption peaks of HLC were 3429, 1650, and $1237 \mathrm{~cm}^{-1}$, which were attributed to the $\mathrm{N}-\mathrm{H}$ stretching vibration peaks, 


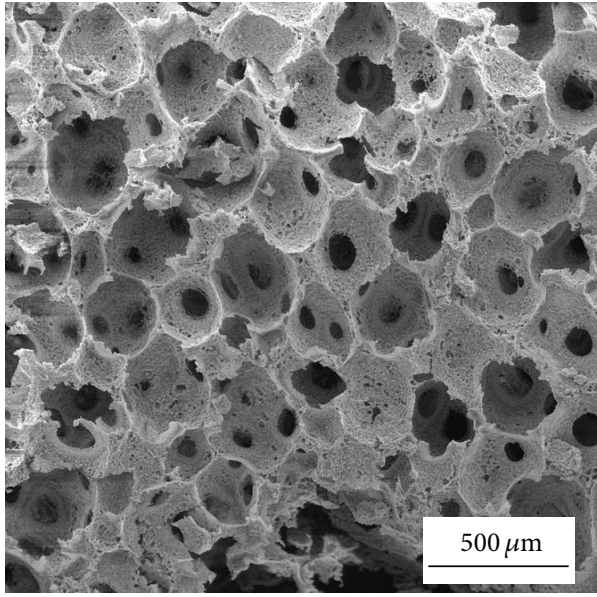

(a)

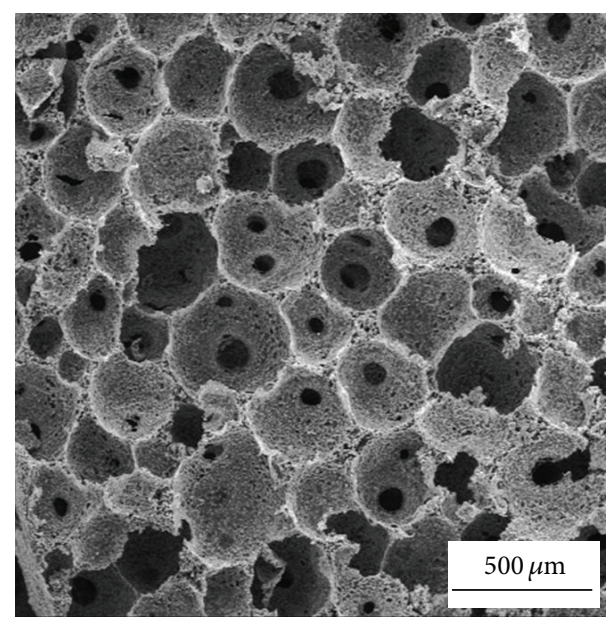

(c)

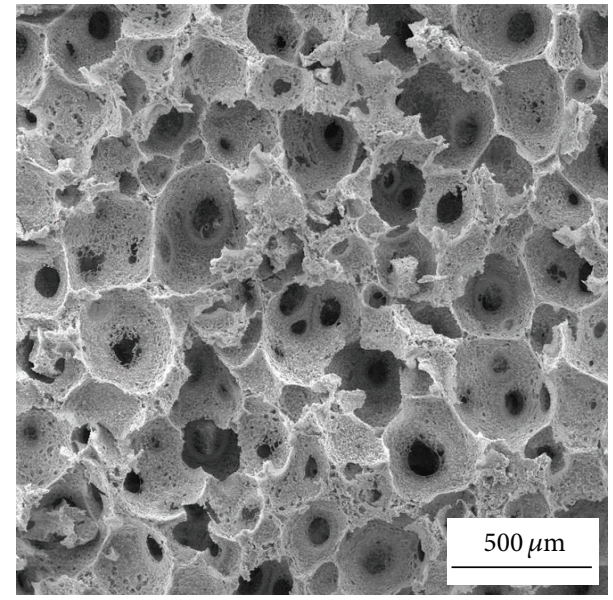

(b)

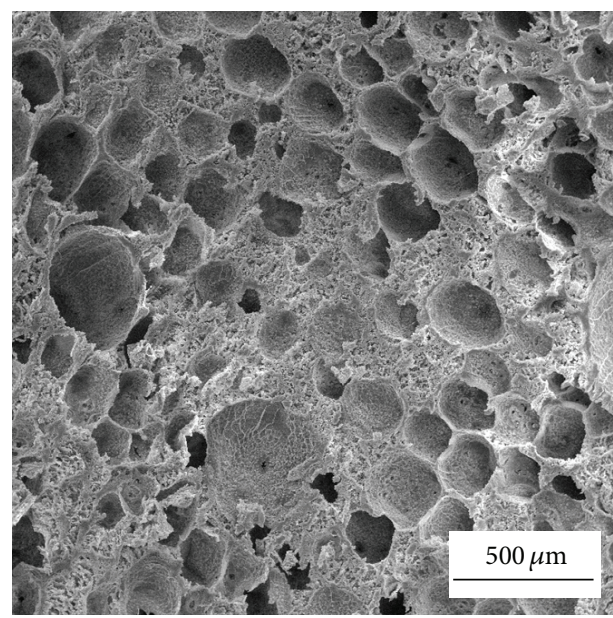

(d)

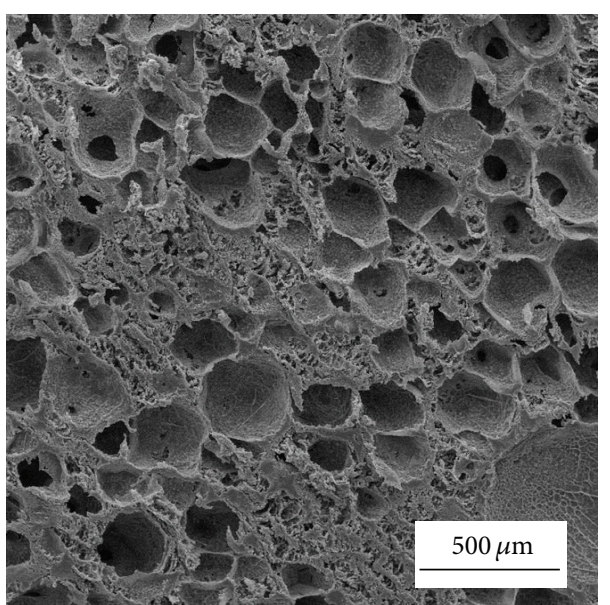

(e)

Figure 1: SEM images of different samples. The ratio of HLC/n-HAp is $1: 2$ (a), $1: 3$ (b), $1: 4$ (c), $1: 5$ (d), and $1: 6$ (e).

$\mathrm{C}=\mathrm{O}$ peaks, and the combined peaks between the $\mathrm{C}-\mathrm{N}$ stretching vibration and $\mathrm{N}-\mathrm{H}$ bending vibration, respectively. These characteristic absorption peaks were also found in the spectra of the composite scaffolds. The scaffolds showed the same characteristic absorption peaks before and after $\mathrm{Co}_{60}$ irradiation.

As observed from the TGA curve (Figure 5(d)), there were two main decreases in the mass of the HLC and 


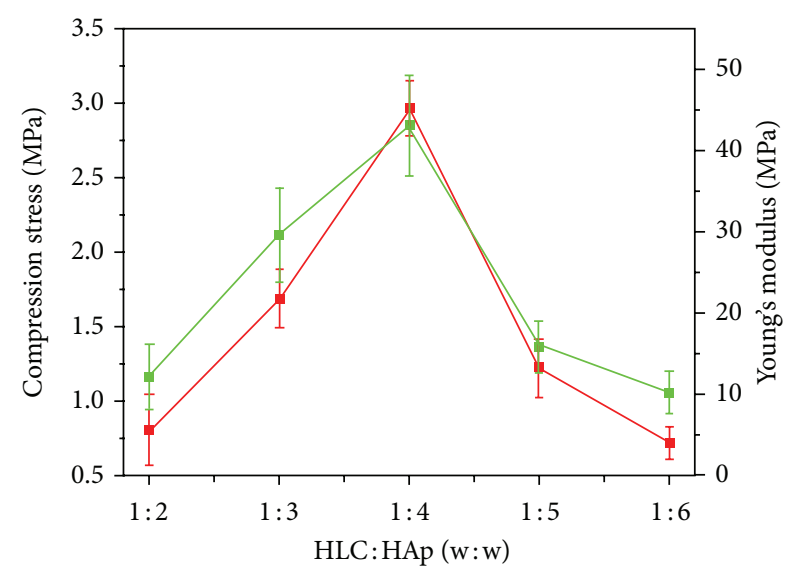

(a)

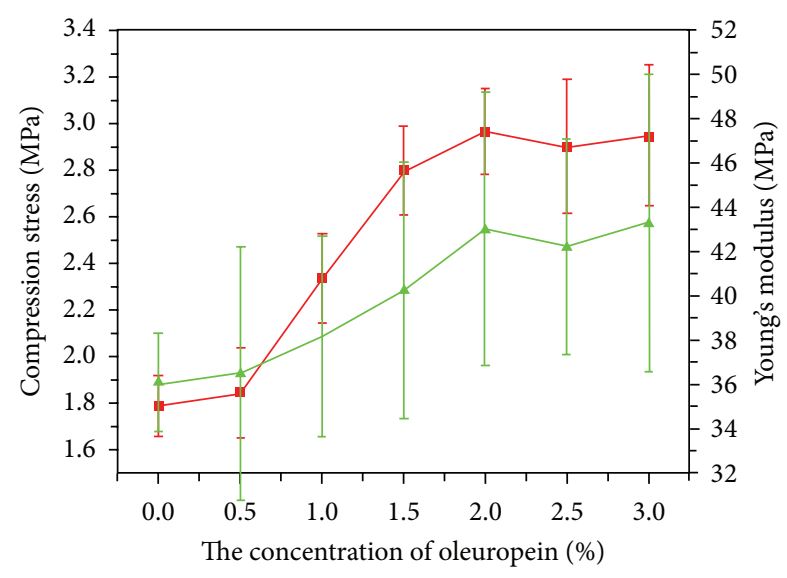

(b)

FIGURE 2: Compressive strength (red) and Young's modulus (green) for the different samples. (a) The composite scaffolds were formed with different $n$-HAp contents using a $2 \%$ solution of oleuropein. (b) The scaffolds were formed with different concentration of oleuropein at an $\mathrm{HlC} / \mathrm{n}-\mathrm{HAp}$ ratio of $1: 4$.

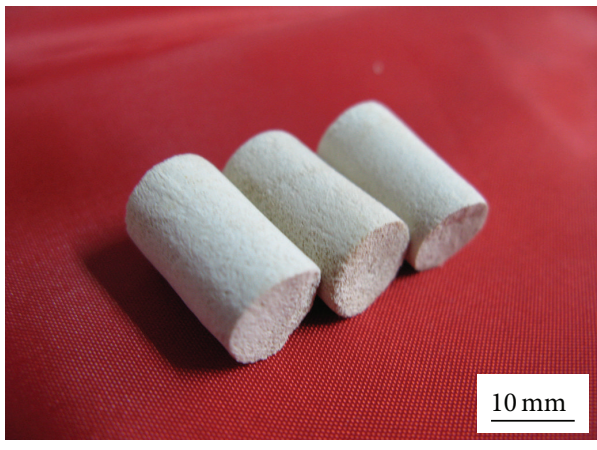

(a)

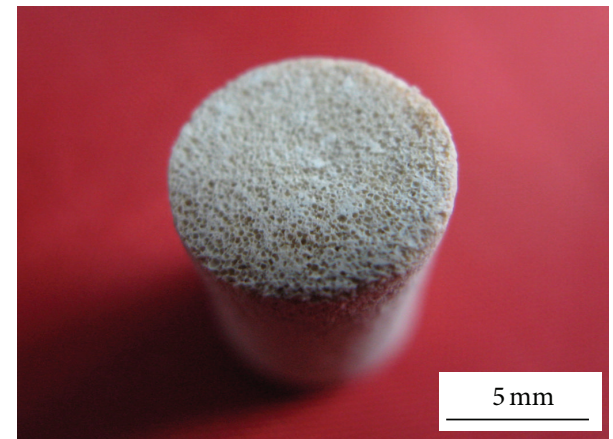

(b)

FIGURE 3: Images of (a) HLC/n-HAp scaffolds and (b) cross-sections with homogeneous pores.

HLC/n-HAp scaffolds (before and after $\mathrm{Co}_{60}$ irradiation). The n-HAp did not have any obvious weight loss. The weight loss for the HLC and the scaffolds below $120^{\circ} \mathrm{C}$ could be attributed to the loss of freely bound water. From $250^{\circ} \mathrm{C}$ to $600^{\circ} \mathrm{C}$, the significant decrease in the mass could be attributed to the decomposition of HLC. Thermal degradation of HLC began at $250^{\circ} \mathrm{C}$, while the onset of thermal degradation for the scaffolds was approximately $300^{\circ} \mathrm{C}$. The electrostatic interaction between HLC and n-HAp, as well as the crosslinking procedure, resulted in an altered thermal degradation profile. The $\mathrm{Co}_{60}$ irradiation had no obvious influence on the thermal stability of the scaffolds.

3.4. Cell Viability and Proliferation. We evaluated the viability and proliferation of MC3T3-E1 cells on the as-prepared scaffolds. Figure 6 shows fluorescence images of the cellscaffolds incubated for 7 and 14 days. With increasing culture time, more area was covered by the cells. It was clear that the MC3T3-E1 cells adhered and proliferated well. As shown in Figure 7, the CCK- 8 assay revealed that the absorbance values increased significantly with culture time. This suggested that the pores and the surfaces of the scaffolds enhanced cell adhesion and proliferation. These results further indicate that the HLC/n-HAp scaffolds are nontoxic and biocompatible.

3.5. Cell Morphology. SEM images of the cells grown on the scaffolds are shown in Figure 8. A greater number of MC3T3E1 cells were observed to attach, spread, and proliferate at 7 and 14 days on the scaffolds. After 7 days of incubation, almost all of the scaffold surfaces were covered with spherical cells. The cells extended more cellular protrusions and connected with each other by way of these structures. After 14 days in culture, the cells produced a large amount of extracellular matrix (ECM), in which the cells were embedded.

\section{Discussion}

A new strategy to fabricate biodegradable scaffolds with more than two components with different physicochemical properties was proposed for bone tissue engineering, when a one-component scaffold cannot suffice $[22,23]$. In this study, an HLC/n-HAp scaffold was fabricated, which preserved the 


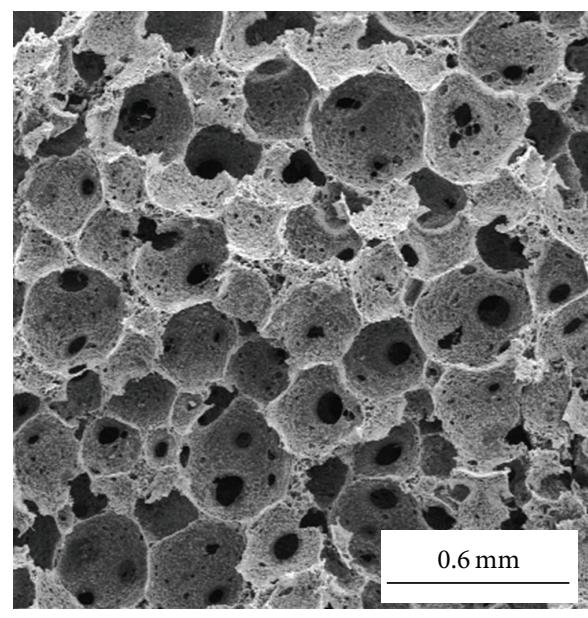

(a)

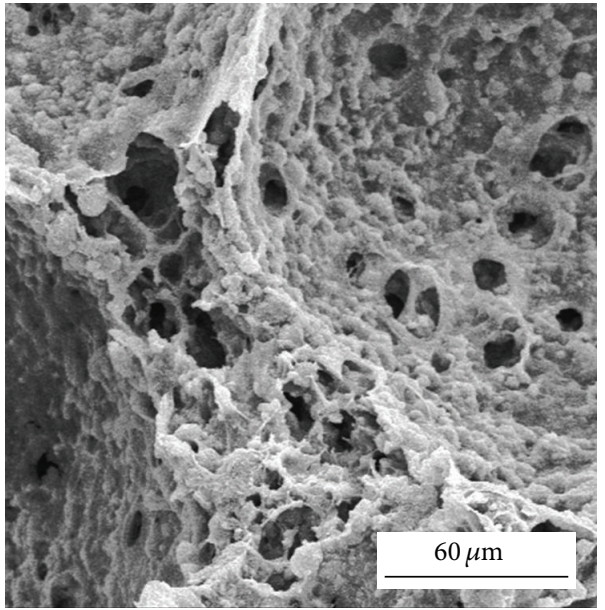

(c)

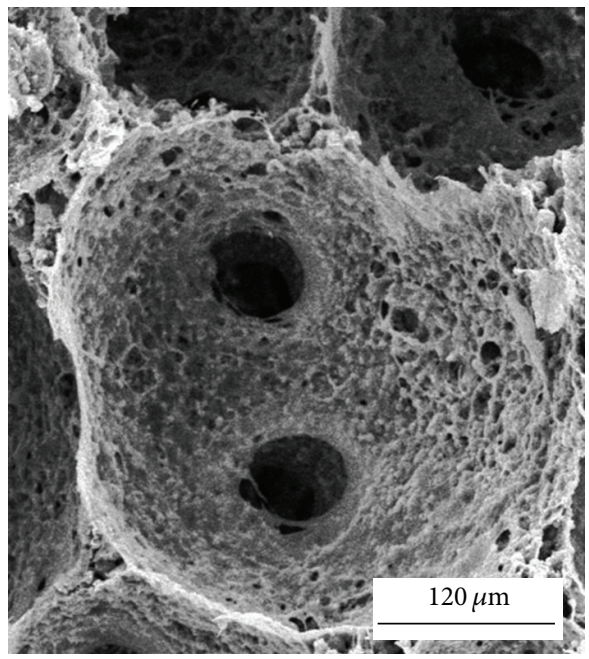

(e)

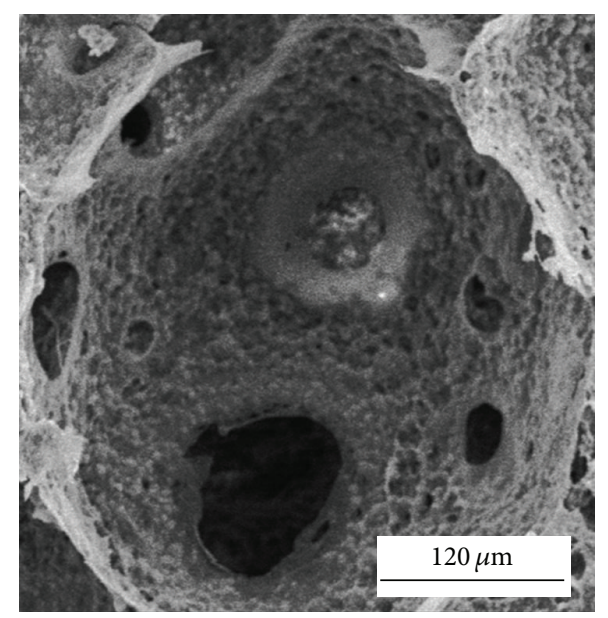

(b)

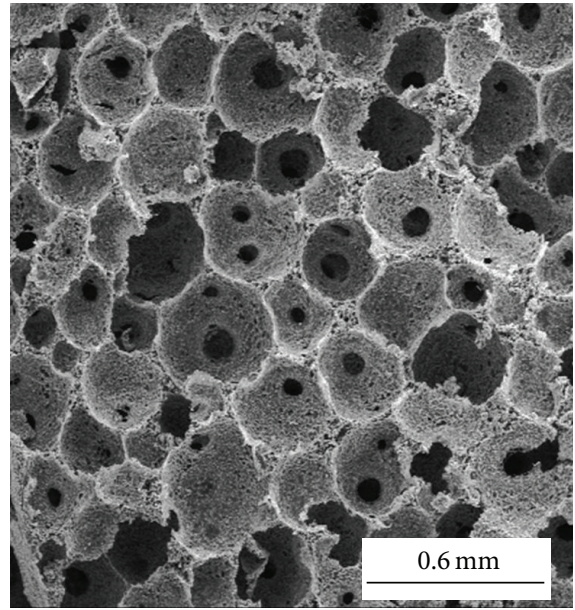

(d)

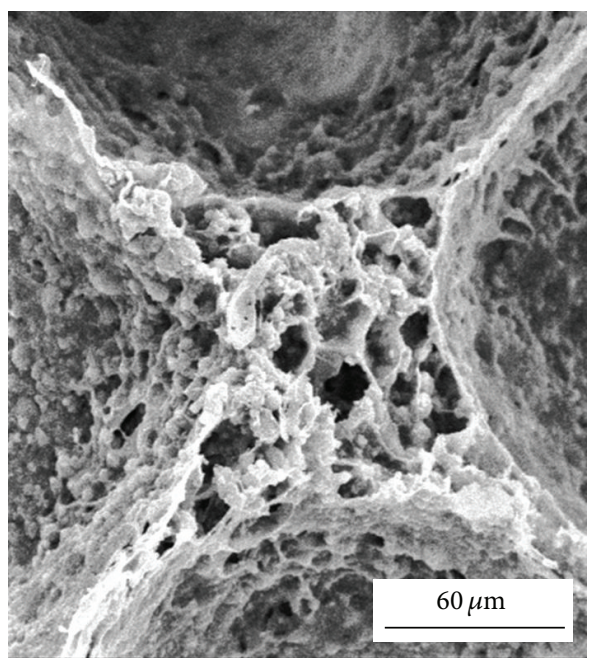

(f)

FIGURE 4: SEM images of the cross-sectional surfaces of the HLC/n-HAp scaffolds before ((a), (b), and (c)) and after ((d), (e), and (f)) $\mathrm{Co}_{60}$ irradiation. ((a), (d)) The scaffolds display interconnected pores ranging in size from 120 to $300 \mu \mathrm{m}$. ((b), (e)) A typical macroporous microstructure for the scaffolds. ((c), (f)) The pore walls in the scaffold. 


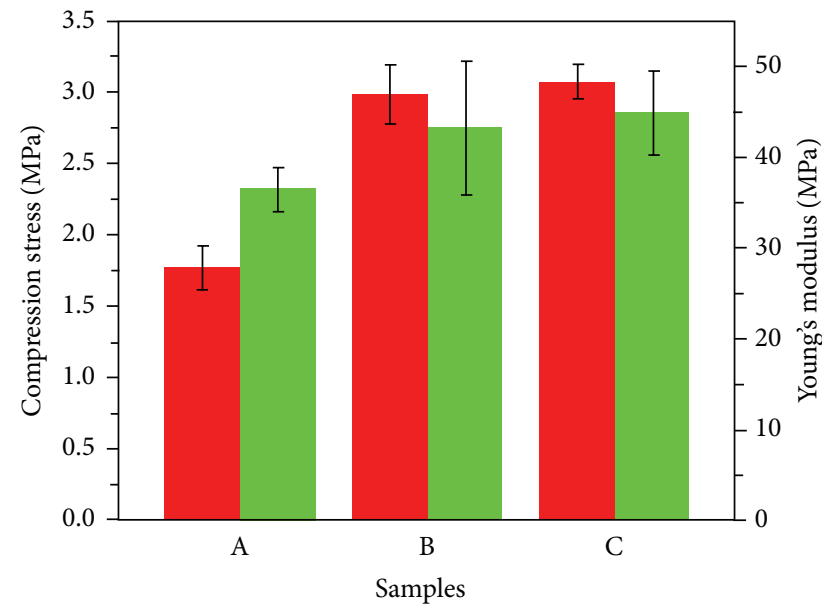

(a)

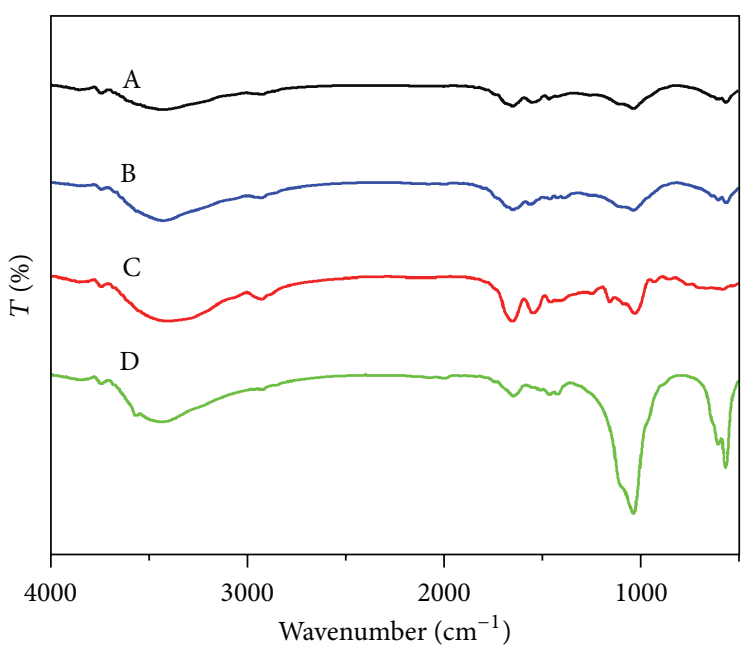

(c)

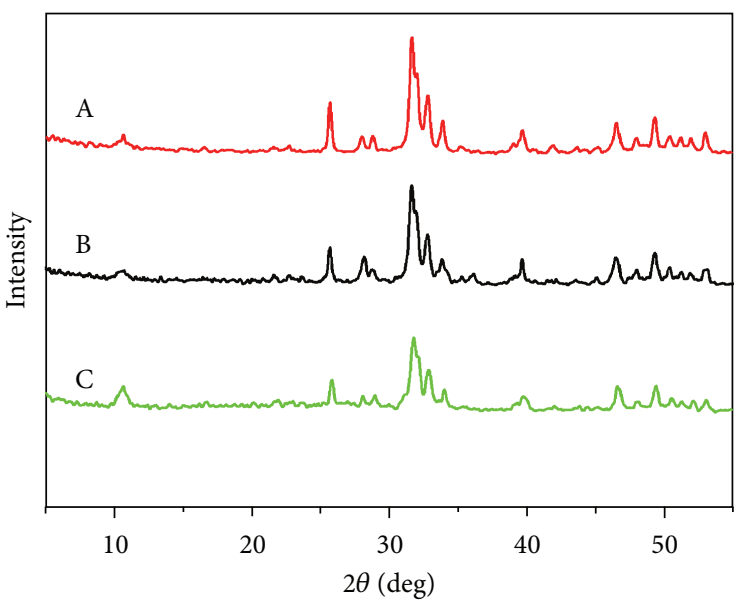

(b)

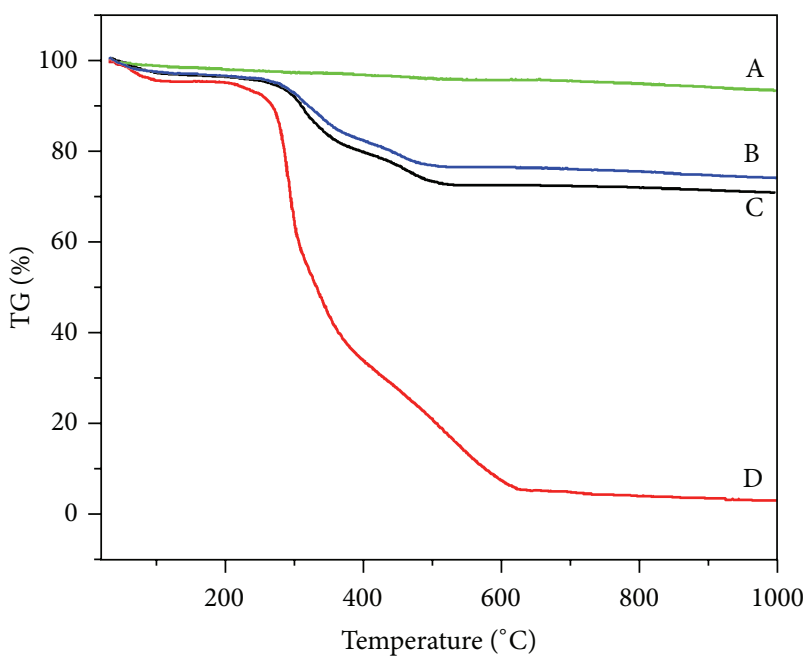

(d)

FiguRE 5: HLC/n-HAp scaffolds characterization. (a) Compressive strength (in red) and Young's modulus (in green) of the scaffolds (A) after and (B) before the cross-linking procedure and (B) before and (C) after $\mathrm{Co}_{60}$ irradiation. (b) XRD patterns for (A) the n-HAp, HLC/n-HAp scaffolds (B) before and (C) after $\mathrm{Co}_{60}$ irradiation. (c) FT-IR spectra for the HLC/n-HAp scaffolds (A) before, (B) after Co $\mathrm{o}_{60}$ irradiation, (C) for HLC, and (D) for n-HAp. (d) TGA curves for the (A) n-HAp, HLC/n-HAp scaffolds (B) after, (C) before $\mathrm{Co}_{60}$ irradiation, and (D) for HLC.

biological characteristics of the HLC and the mechanical properties and osteoconductivity of the n-HAp. We fabricated highly porous $3 \mathrm{D}$ structure scaffolds with homogeneous and interconnected pores by slow cooling and vacuum freezedrying. These water-soluble scaffolds were transformed into water-insoluble scaffolds using the natural cross-linking agent oleuropein. After cross-linking, another freeze-drying step was performed.

In bone tissue engineering, it is important to have the appropriate pore sizes for cell adhesion and tissue reconstruction. The pore size greatly affects the cellular activity. Even subtle changes in pore size may have significant effects on cell adhesion [24]. It has been reported that small pore sizes can limit cell migration and colonization $[25,26]$, vascular ingrowth, and nutrient and water transfer [27]. Furthermore, smaller pore sizes can influence the cell distribution in the scaffolds. However, if the pore size is too large, it can influence cell adhesion. Large pore sizes affect the construct and mechanical properties of the scaffolds. Moreover, it is difficult to create a suitable environment for the production of ECM in scaffolds with large pore sizes [28]. Freezedrying has proved to be a gentle drying method that can be used to obtain scaffolds with appropriate pore size and interconnectivity [29]. As shown in Figures 3(b) and 4, the pores of the HLC/n-HAp scaffolds are homogeneous and interconnected. The SEM images (Figure 8) indicate that cells are contained within the scaffold pores, forming bridges over the pores (Figure $8(\mathrm{e})$ ). The cells connected with neighboring cells by way of the pore structures. The HLC/n-HAp scaffolds promoted MC3T3-E1 ECM production, which is essential for bone formation.

An ideal tissue engineering scaffold provides sufficient mechanical properties and high porosity, both of which are key determinant factors for implantation. Proper mechanical 


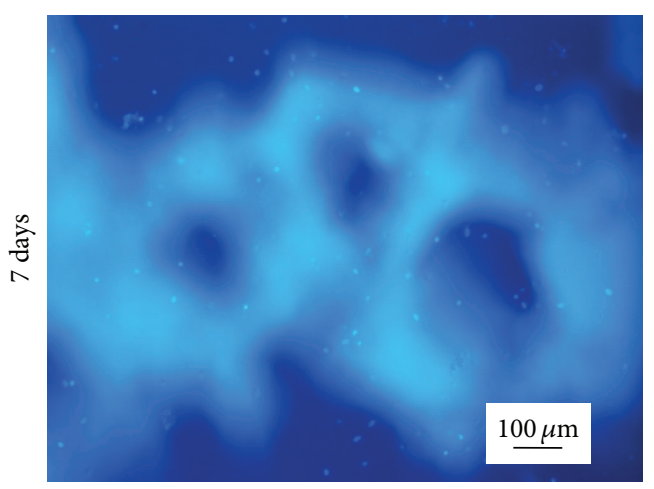

(a)

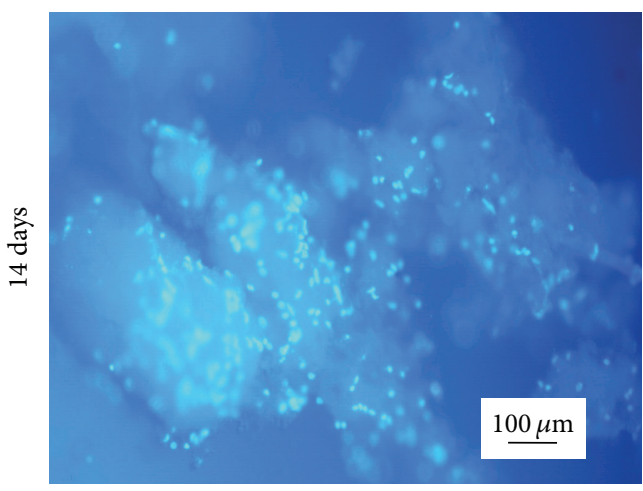

(c)

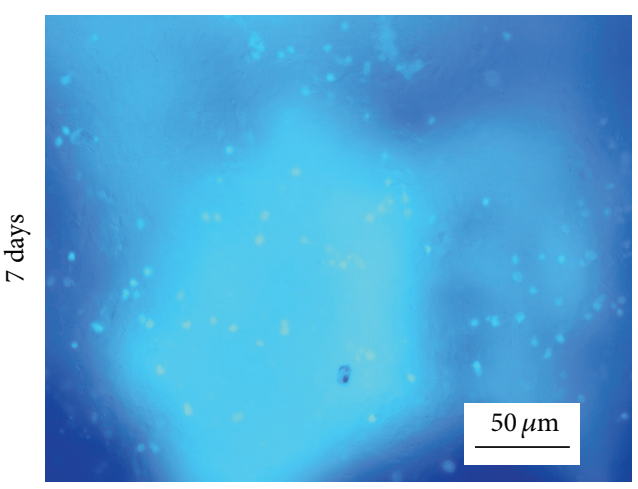

(b)

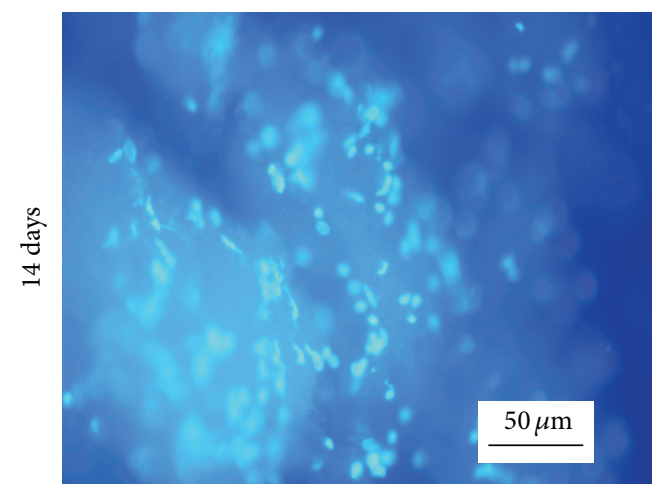

(d)

FIGURE 6: Fluorescence images of MC3T3-E1 cells cultured on the HLC/n-HAp scaffolds for ((a), (b)) 7 days and ((c), (d)) 14 days. ((a), (c)) Low magnification views of the cell-scaffolds. ((b), (d)) Magnified views of the cells on the pore walls of the scaffolds. The scale bars in the left column and right column represent $100 \mu \mathrm{m}$ and $50 \mu \mathrm{m}$, respectively.

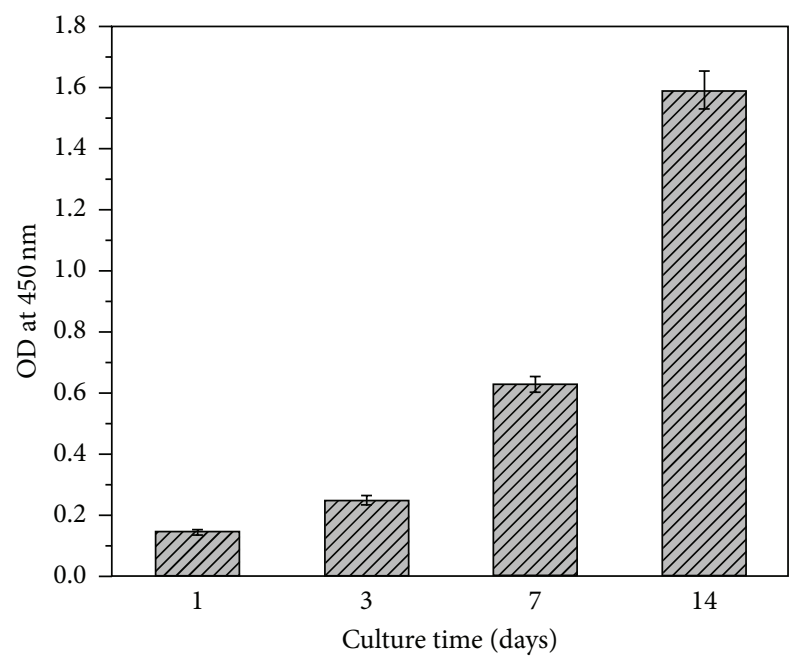

FIGURE 7: CCK-8 assay for attachment and proliferation of MC3T3E1 cells on the HLC/n-HAp scaffolds over various incubation periods. Error bars represent means $\pm \operatorname{SD}(n=5)$.

properties and porosity are needed to supply temporary support for vascularization and tissue ingrowth [30]. However, exceedingly high porosity can reduce the mechanical property of the scaffolds. The compressive strength is also closely tied to the proportion of inorganic and organic ingredients [31]. In this case, an HLC and n-HAp ratio of $1: 4$ was employed to obtain a better scaffold with a porosity of $73.6 \pm 2.3 \%$ and a mechanical strength of $3 \mathrm{MPa}$. In addition, the cross-linking process further contributed to the mechanical properties, as shown in Figure 5(a).

The rate and quality of new tissue formation are greatly affected by the initial cell adhesion to the scaffolds. Cell adhesion is influenced by the scaffold surface characteristics, such as the surface chemical composition, surface topography, surface multicavities, and roughness [32]. Higher initial cell adhesion requires adhesion proteins that are abundant in the serum. The n-HAp nanoscale crystals have a high binding affinity to the serum proteins [33]. When a higher degree of proteins is absorbed on the scaffold surface, it could provide more attachment sites for the cells. In this study, the use of nanoscale n-HAp greatly promoted cell adhesion. In addition, the surface roughness (Figures 4(c) and 4(f)) could improve cell-biomaterial response, adding cellular adhesion, growth, migration, and differentiation. The cell spreading and proliferation significantly increase on rough surfaces, compared to smoother surfaces [32]. As shown in the SEM images, the cells established close contact with the scaffold surface, displaying spherical morphologies (Figures 8(c) and $8(\mathrm{f})$ ) with numerous filopodia and lamellipodia (Figures $8(\mathrm{~d})$, $8(\mathrm{e})$, and $8(\mathrm{f}))$. 


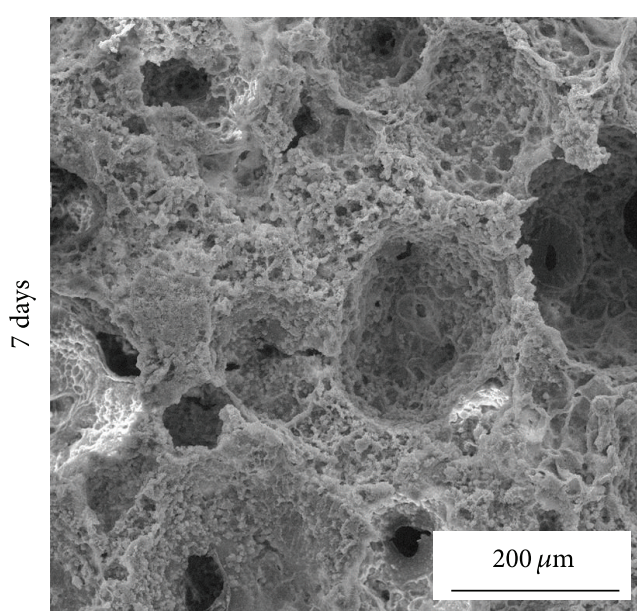

(a)

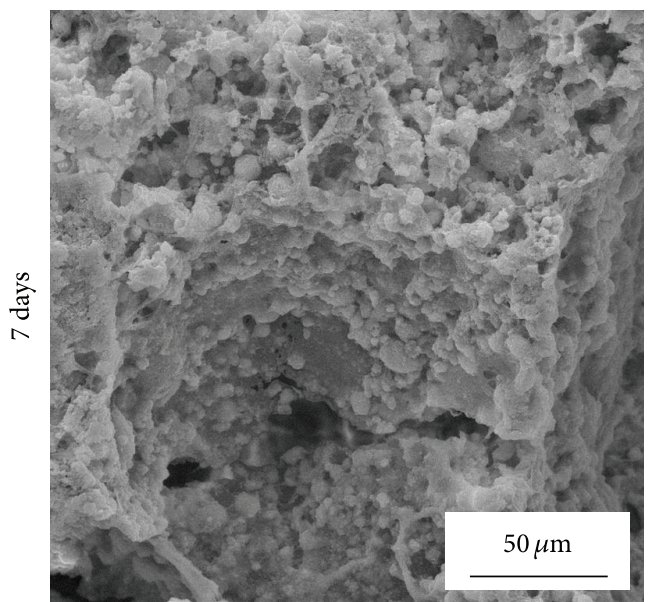

(c)

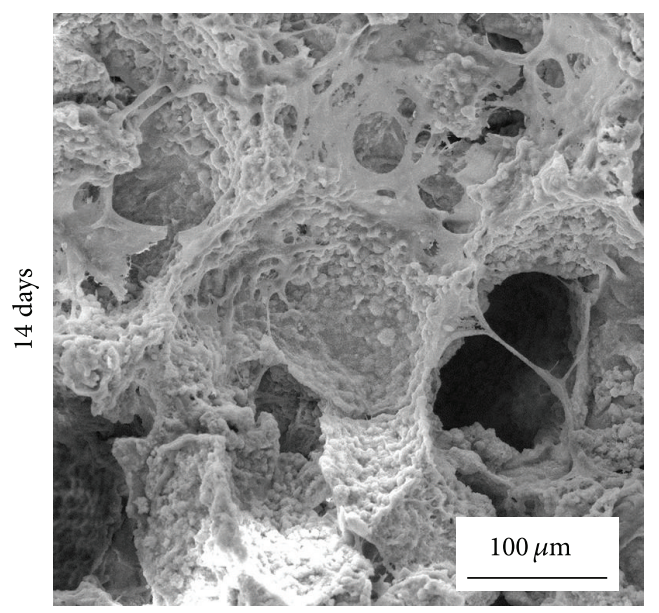

(e)

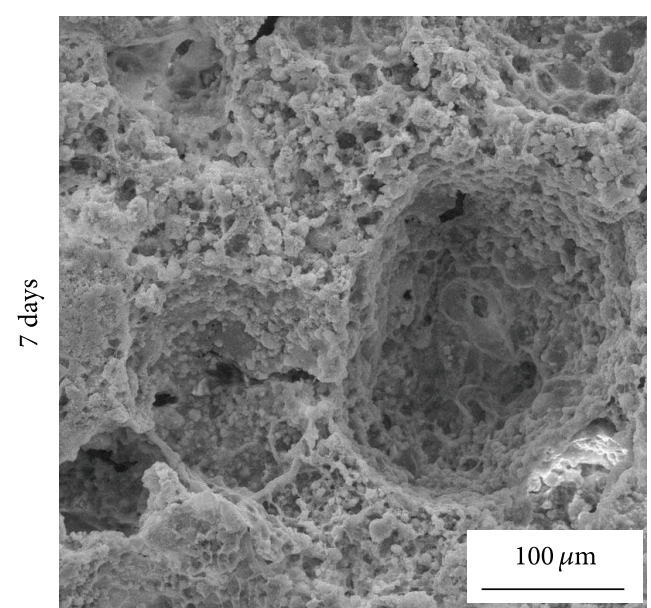

(b)

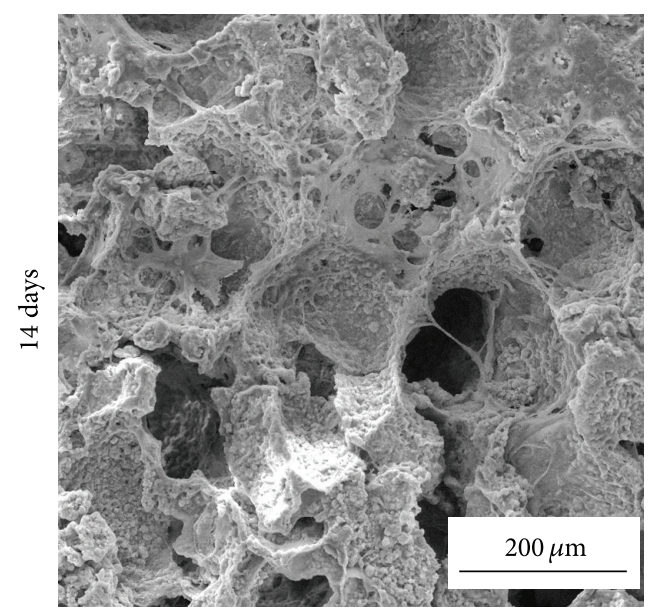

(d)

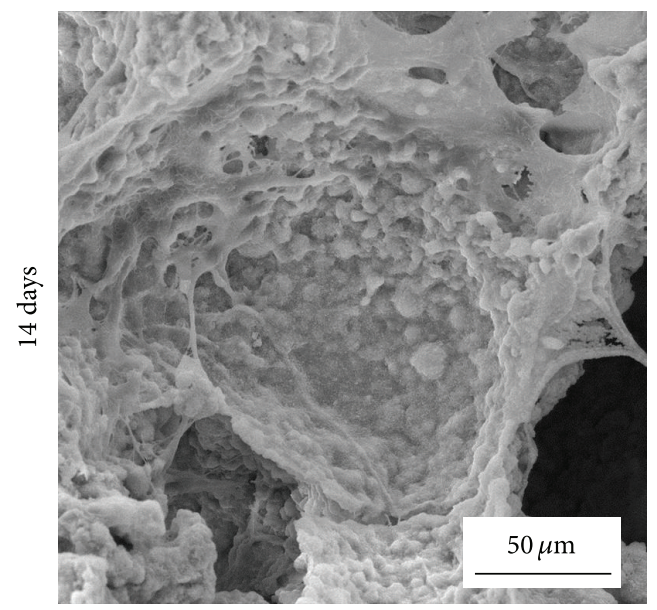

(f)

FIGURE 8: SEM images of MC3T3-E1 cells cultured on the HLC/n-HAp scaffolds for 7 ((a), (b), and (c)) and 14 ((d), (e), and (f)) days. The scale bars in the left column, middle column, and right column represent $200 \mu \mathrm{m}, 100 \mu \mathrm{m}$, and $50 \mu \mathrm{m}$, respectively. 
Cytotoxicity must be evaluated for all scaffolds used in bone tissue engineering. In this study, the natural crosslinking agent oleuropein was used. The most common crosslinking agents, glutaraldehyde and carbodiimide, are cytotoxic and may negatively affect the cells [34]. In our study, the natural cross-linking agent, oleuropein, was assessed using the CCK-8 assay. As shown in Figure 7, the composite HLC/n-HAp scaffolds are biocompatible and can thus serve as suitable materials for biomedical applications.

\section{Conclusion}

A composite HLC/n-HAp system with interconnected pores was prepared by cross-linking. The as-prepared scaffolds were characterized using SEM, XRD, FTIR, and TGA. In addition, the porosity, compressive strength, cytotoxicity, cell adhesion, and proliferation of the scaffolds were investigated. The scaffolds had interconnected pores ranging from 120 to $300 \mu \mathrm{m}$. The cells attached well to the pore walls, extending cellular protrusions and producing large amounts of ECM. The HLC/n-HAp scaffolds were noncytotoxic and biocompatible. The scaffolds preserved the outstanding biological characteristics of HLC and the excellent osteoconductivity of n-HAp. Therefore, the HLC/n-HAp scaffolds obtained by oleuropein cross-linking have potential for use in bone tissue engineering.

\section{Conflict of Interests}

The authors declare that there is no conflict of interests regarding the publication of this paper.

\section{Authors' Contribution}

Hui Fan and Junfeng Hui are co-first authors; they contributed equally to this paper.

\section{Acknowledgments}

This study was financially supported by the National Natural Science Foundation of China (21276210, 21106112, 21106111, 21106114, 31000019, 21206135, and 21376190); the National High Technology Research and Development Program of China (863 Program, 2014AA02108); the Shaanxi Provincial Scientific Technology Research and Development Program (2007K06-03, 2011JE003, 2012JQ2019, 2012KJXX-28, 2013KJXX-28, and 2011JQ4026); and the Scientific Research Program of Shaanxi Provincial Department of Education, China (12JK0449, 13JS106, 13JS105, 13JS104, and 2013JK0696).

\section{References}

[1] R. Z. LeGeros, "Calcium phosphate-based osteoinductive materials," Chemical Reviews, vol. 108, no. 11, pp. 4742-4753, 2008.

[2] W. G. de Long Jr., T. A. Einhorn, K. Koval et al., "Bone grafts and bone graft substitutes in orthopaedic trauma surgery: a critical analysis," Journal of Bone and Joint Surgery A, vol. 89, no. 3, pp. 649-658, 2007.
[3] V. Mouriño and A. R. Boccaccini, "Bone tissue engineering therapeutics: controlled drug delivery in three-dimensional scaffolds," Journal of the Royal Society Interface, vol. 7, no. 43, pp. 209-227, 2010.

[4] J. F. A. Valente, T. A. M. Valente, P. Alves, P. Ferreira, A. P. Silva, and I. J. Correia, "Alginate based scaffolds for bone tissue engineering," Materials Science and Engineering C, vol. 32, no. 8, pp. 2596-2603, 2012.

[5] H. Seyednejad, D. Gawlitta, W. J. A. Dhert, C. F. van Nostrum, T. Vermonden, and W. E. Hennink, "Preparation and characterization of a three-dimensional printed scaffold based on a functionalized polyester for bone tissue engineering applications," Acta Biomaterialia, vol. 7, no. 5, pp. 1999-2006, 2011.

[6] G. Wei and P. X. Ma, "Structure and properties of nanohydroxyapatite/polymer composite scaffolds for bone tissue engineering," Biomaterials, vol. 25, no. 19, pp. 4749-4757, 2004.

[7] K. S. Jack, S. Velayudhan, P. Luckman, M. Trau, L. Grøndahl, and J. Cooper-White, "The fabrication and characterization of biodegradable HA/PHBV nanoparticle-polymer composite scaffolds," Acta Biomaterialia, vol. 5, no. 7, pp. 2657-2667, 2009.

[8] D. W. Hutmacher, "Scaffolds in tissue engineering bone and cartilage," Biomaterials, vol. 21, no. 24, pp. 2529-2543, 2000.

[9] J. R. Jones and L. L. Hench, "Regeneration of trabecular bone using porous ceramics," Current Opinion in Solid State and Materials Science, vol. 7, no. 4-5, pp. 301-307, 2003.

[10] V. Karageorgiou and D. Kaplan, "Porosity of 3D biomaterial scaffolds and osteogenesis," Biomaterials, vol. 26, no. 27, pp. 5474-5491, 2005.

[11] X. Hua, D. Fan, Y. Luo et al., "Kinetics of high cell density fed-batch culture of recombinant escherichia coli producing human-like collagen," Chinese Journal of Chemical Engineering, vol. 14, no. 2, pp. 242-247, 2006.

[12] C. Zhu, D. Fan, X. Ma et al., "Effects of chitosan on properties of novel human-like collagen/chitosan hybrid vascular scaffold," Journal of Bioactive and Compatible Polymers, vol. 24, no. 6, pp. 560-576, 2009.

[13] C. Zhu, D. Fan, Z. Duan et al., "Initial investigation of novel human-like collagen/chitosan scaffold for vascular tissue engineering," Journal of Biomedical Materials Research A, vol. 89, no. 3, pp. 829-840, 2009.

[14] Y. Wang, F. Z. Cui, K. Hu, X. D. Zhu, and D. D. Fan, "Bone regeneration by using scaffold based on mineralized recombinant collagen," Journal of Biomedical Materials Research B: Applied Biomaterials, vol. 86, no. 1, pp. 29-35, 2008.

[15] X. Li, X. Ma, D. Fan, and C. Zhu, "New suitable for tissue reconstruction injectable chitosan/collagen-based hydrogels," Soft Matter, vol. 8, no. 14, pp. 3781-3790, 2012.

[16] K. Hu, F. Cui, Q. Lv et al., "Preparation of fibroin/recombinant human-like collagen scaffold to promote fibroblasts compatibility," Journal of Biomedical Materials Research A, vol. 84, no. 2, pp. 483-490, 2008.

[17] P. N. de Aza, Z. B. Luklinska, C. Santos, F. Guitian, and S. de Aza, "Mechanism of bone-like formation on a bioactive implant in vivo," Biomaterials, vol. 24, no. 8, pp. 1437-1445, 2003.

[18] T. Livingston, P. Ducheyne, and J. Garino, "In vivo evaluation of a bioactive scaffold for bone tissue engineering," Journal of Biomedical Materials Research, vol. 62, no. 1, pp. 1-13, 2002.

[19] R. O. Beauchamp Jr., M. B. G. St. Clair, T. R. Fennell, D. O. Clarke, K. T. Morgan, and F. W. Kari, "A critical review of the toxicology of glutaraldehyde," Critical Reviews in Toxicology, vol. 22, no. 3-4, pp. 143-174, 1992. 
[20] J. C. Isenburg, N. V. Karamchandani, D. T. Simionescu, and N. R. Vyavahare, "Structural requirements for stabilization of vascular elastin by polyphenolic tannins," Biomaterials, vol. 27, no. 19, pp. 3645-3651, 2006.

[21] C. Puel, A. Quintin, A. Agalias et al., "Olive oil and its main phenolic micronutrient (oleuropein) prevent inflammationinduced bone loss in the ovariectomised rat," British Journal of Nutrition, vol. 92, no. 1, pp. 119-127, 2004.

[22] K. Rezwan, Q. Z. Chen, J. J. Blaker, and A. R. Boccaccini, "Biodegradable and bioactive porous polymer/inorganic composite scaffolds for bone tissue engineering," Biomaterials, vol. 27, no. 18, pp. 3413-3431, 2006.

[23] C. Xu, P. Su, X. Chen et al., "Biocompatibility and osteogenesis of biomimetic Bioglass-Collagen-Phosphatidylserine composite scaffolds for bone tissue engineering," Biomaterials, vol. 32, no. 4, pp. 1051-1058, 2011.

[24] C. M. Murphy, M. G. Haugh, and F. J. O'Brien, “The effect of mean pore size on cell attachment, proliferation and migration in collagen-glycosaminoglycan scaffolds for bone tissue engineering," Biomaterials, vol. 31, no. 3, pp. 461-466, 2010.

[25] E. D. Boland, J. A. Matthews, K. J. Pawlowski, D. G. Simpson, G. E. Wnek, and G. L. Bowlin, "Electrospinning collagen and elastin: preliminary vascular tissue engineering," Frontiers in Bioscience, vol. 9, pp. 1422-1432, 2004.

[26] A. S. Badami, M. R. Kreke, M. S. Thompson, J. S. Riffle, and A. S. Goldstein, "Effect of fiber diameter on spreading, proliferation, and differentiation of osteoblastic cells on electrospun poly(lactic acid) substrates," Biomaterials, vol. 27, no. 4, pp. 596606, 2006.

[27] J. H. Brauker, V. E. Carr-Brendel, L. A. Martinson, J. Crudele, W. D. Johnston, and R. C. Johnson, "Neovascularization of synthetic membranes directed by membrane microarchitecture," Journal of Biomedical Materials Research, vol. 29, no. 12, pp. 15171524, 1995.

[28] S. Grad, L. Kupcsik, K. Gorna, S. Gogolewski, and M. Alini, “The use of biodegradable polyurethane scaffolds for cartilage tissue engineering: potential and limitations," Biomaterials, vol. 24, no. 28, pp. 5163-5171, 2003.

[29] J. S. Mao, L. G. Zhao, Y. J. Yin, and K. D. Yao, "Structure and properties of bilayer chitosan-gelatin scaffolds," Biomaterials, vol. 24, no. 6, pp. 1067-1074, 2003.

[30] A. Nemati Hayati, S. M. Hosseinalipour, H. R. Rezaie, and M. A. Shokrgozar, "Characterization ofpoly(3-hydroxybutyrate)/ nano-hydroxyapatite composite scaffolds fabricated without the use of organic solvents for bone tissue engineering applications," Materials Science and Engineering C, vol. 32, no. 3, pp. 416-422, 2012.

[31] B. Li, L. Huang, X. Wang, J. Ma, and F. Xie, "Biodegradation and compressive strength of phosphorylated chitosan/chitosan/hydroxyapatite bio-composites," Materials and Design, vol. 32, no. 8-9, pp. 4543-4547, 2011.

[32] S. Huang and X. Fu, "Cell behavior on microparticles with different surface morphology," Journal of Alloys and Compounds, vol. 493, no. 1-2, pp. 246-251, 2010.

[33] H.-W. Kim, H.-E. Kim, and V. Salih, "Stimulation of osteoblast responses to biomimetic nanocomposites of gelatinhydroxyapatite for tissue engineering scaffolds," Biomaterials, vol. 26, no. 25, pp. 5221-5230, 2005.

[34] J. E. Gough, C. A. Scotchford, and S. Downes, "Cytotoxicity of glutaraldehyde crosslinked collagen/poly(vinyl alcohol) films is by the mechanism of apoptosis," Journal of Biomedical Materials Research, vol. 61, no. 1, pp. 121-130, 2002. 


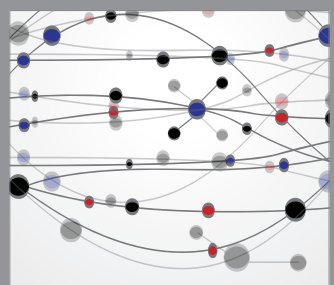

The Scientific World Journal
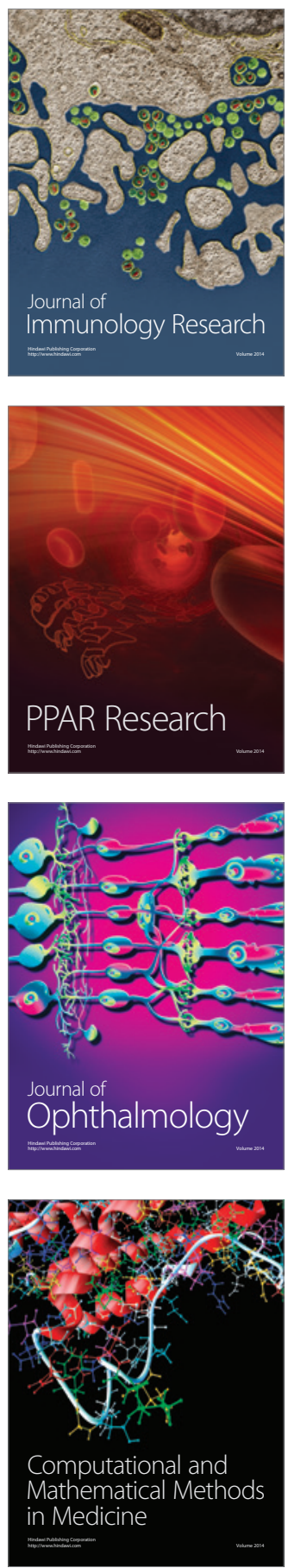

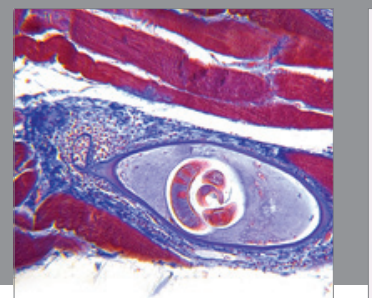

Gastroenterology

Research and Practice
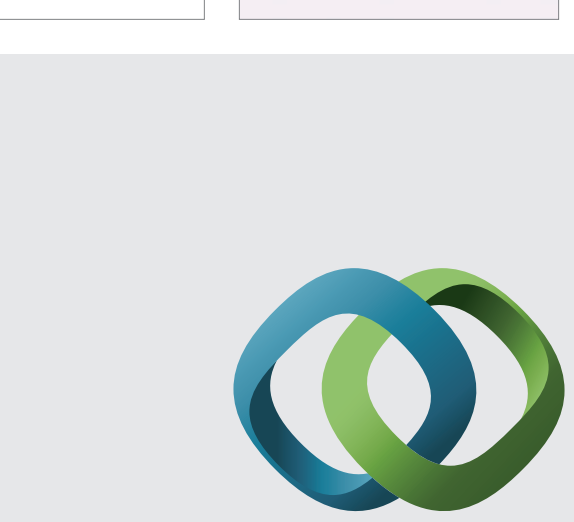

\section{Hindawi}

Submit your manuscripts at

http://www.hindawi.com
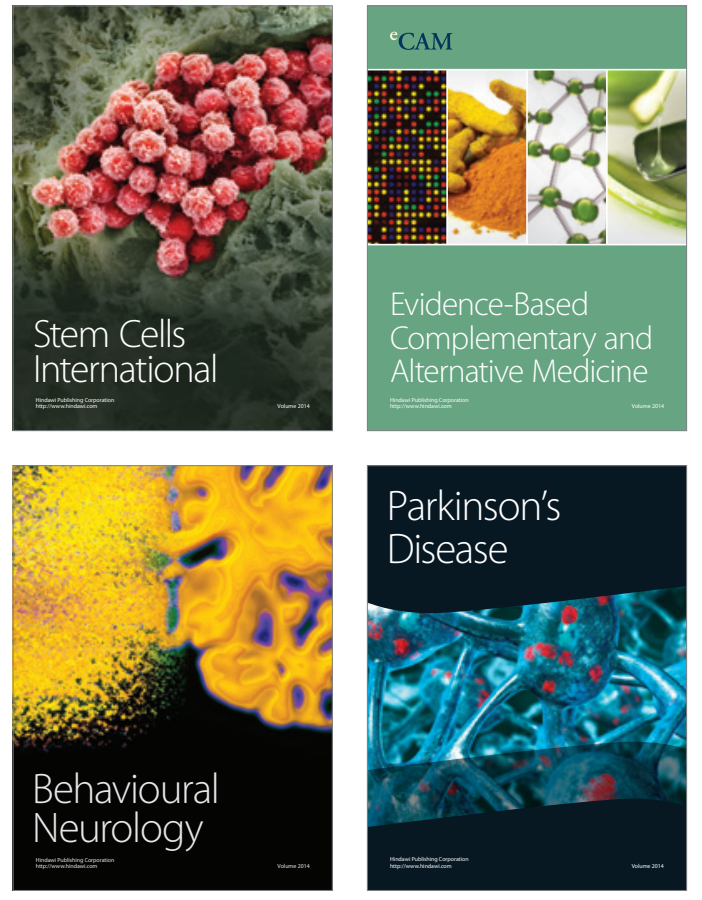
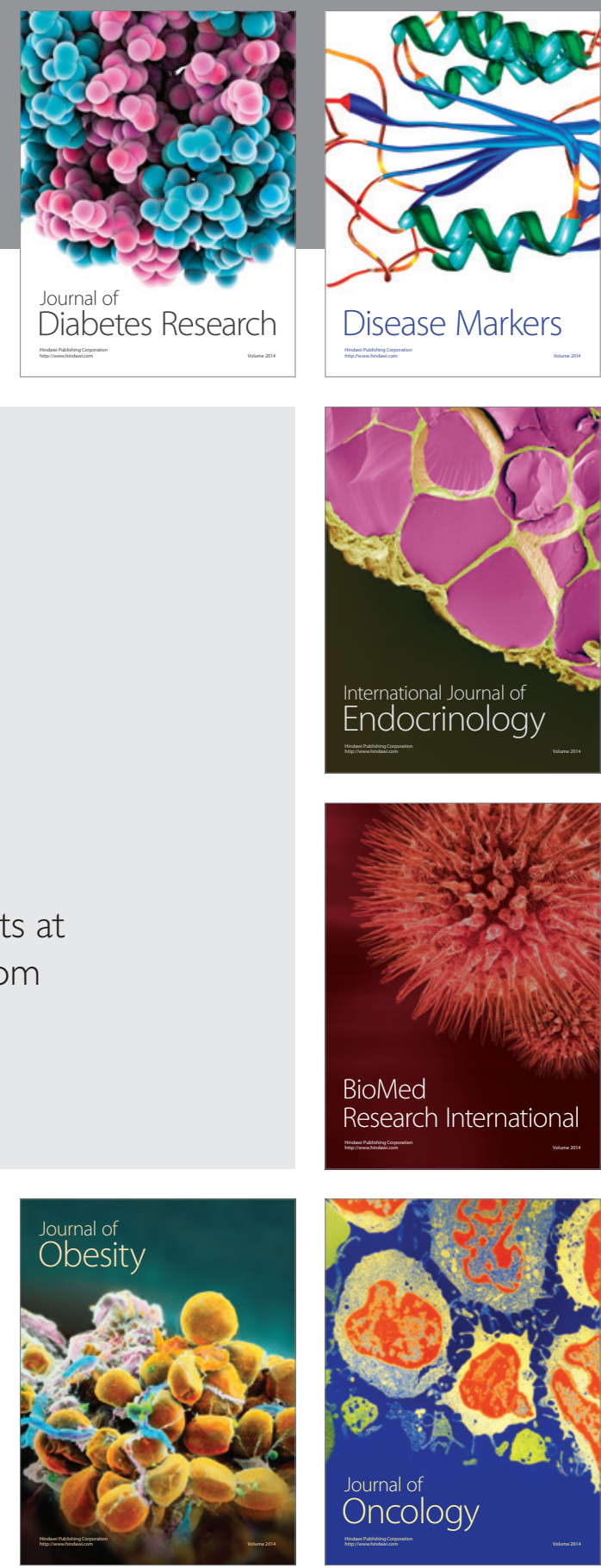

Disease Markers
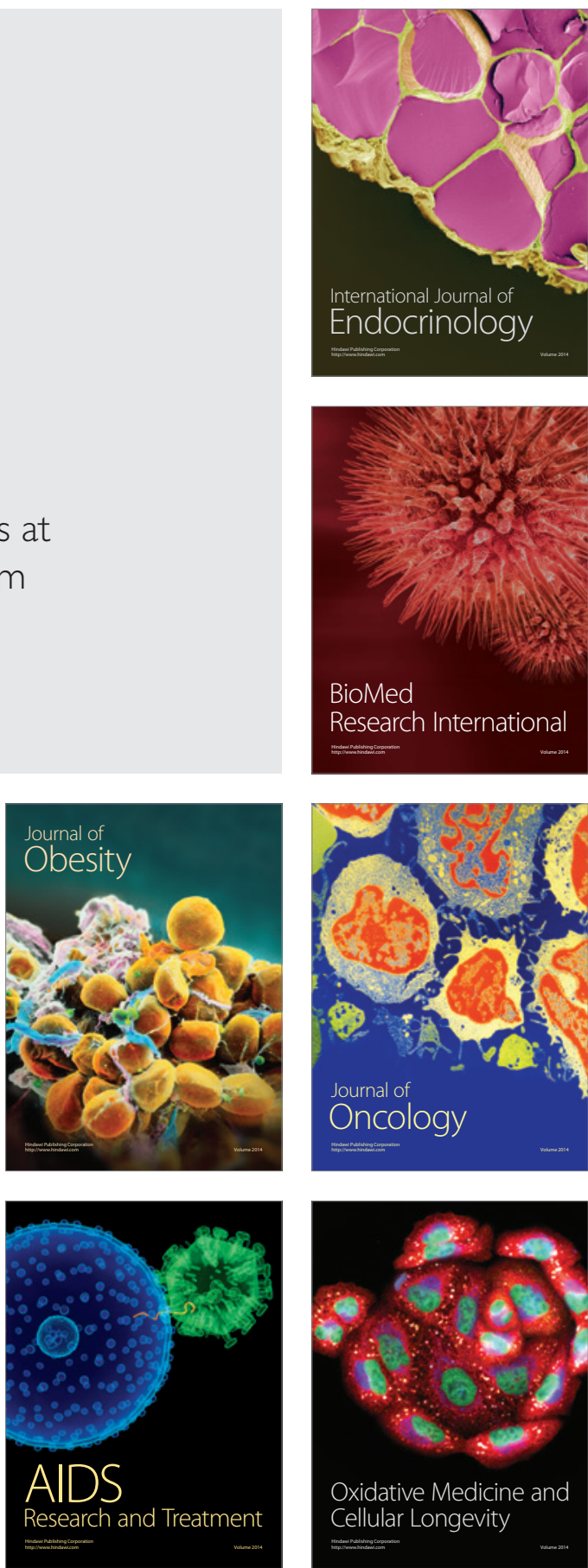